\title{
Technologies of Serendipity
}

\author{
PAUL FYFE
}

In reckoning with the digital restructuring of the scholarly discourse network circa 2004, Patrick Leary begins with a story. It is a story about how, thanks to web discovery and email contacts, scholarship on Letitia Elizabeth Landon took a major turn. This happened because of the "fortuitous electronic connections" of people and documents facilitated by the internet. ${ }^{\mathrm{I}}$ And making sense of this experience, rather than detailing specific resources for digital scholarship, becomes Leary's abiding concern in "Googling the Victorians." His essay ponders a "profound shift" towards casual discovery, "a serendipity of unexpected connections to both information and people that is becoming increasingly central to the progress of Victorian research." ${ }^{2}$ If, in the subtitle to their 1982 volume The Victorian Periodical Press, Joanne Shattock and Michael Wolff nominate "Samplings and Soundings" as our only reasonable approach, Leary begins to clarify how such casual discoveries should not merely be viewed as symptoms of trying to find specifics amid superabundance, whether in terms of the Victorian archive or networked digital information. ${ }^{3}$ Instead, that characteristic research experience has been absorbed into the technological routines of how we work now. In other words, chance discovery is not a bug; it is a feature. It is the very condition of "Googling the Victorians," as Leary calls it. A decade later, we find ourselves deeper in the networked experience of such unexpected connections, with more perspective that allows us to acknowledge, critique, and perhaps even credit serendipity as scholarly technique.

"Googling the Victorians" also reveals the scholar's reflex to enfold fortuitous discoveries within descriptive explanation. The essay shows a consistent dynamic between the item of scholarly interest, serendipitously found, and the narrative in which the researcher governs the unexpected. In drawing this connection, Leary makes a crucial distinction between serendipity and randomness. If we all have random encounters all the time, serendipity requires recognizing such an encounter for its meaning, requir- 
ing an interpretive context to place the unexpected within an explanatory framework. ${ }^{4}$ Digital materials have proliferated since "Googling the Victorians" but so too have the contexts in which we encounter them, including the very tools and platforms which circumscribe the digital objects they serve. ${ }^{5}$ Such is the lament of many teachers: students privilege quick access ("Googling") over research methods contextualized by institutional structures (in other words, libraries), which have served print scholarship for decades and longer. As Leary noted, such is the boon of many researchers, now awash in volumes of materials at scales unseen since the nineteenth century's own profusion of printed objects, periodicals especially. Contexts-or how to reconcile new information within a horizon of knowledge or questioning-have become as crucial for digital scholarship as access to digital objects themselves (if not more so). What we need to teach now and what researchers themselves need to cultivate is the "curatorial intelligence" to assess and recontextualize digital objects discovered through techniques now including—even privileging—serendipity. ${ }^{6}$

The remainder of this short essay will sketch out how, since Leary's article, serendipity has been "operationalized," or built into, the research platforms which reflexively shape our methods and become part of the ordinariness of scholarly practice. ${ }^{7}$ While many early sites on the web featured random discovery, only lately have serendipitous machines been purpose-built for academic work. ${ }^{8}$ Certain scholarly sites now spotlight random access as a valid entry point to their contents, such as the Oxford English Dictionary's "Lost for Words" feature, previously subtitled "Get a Random Entry." Apparently there are fans of randomness at Oxford University Press, as the Dictionary of National Biography-Leary's own ultimate example in 2004-now also offers a "Get a Life at Random" feature, or "Get a Life" for short. ${ }^{9}$ The information science and library community has also driven these developments. For example, the Trove project of the National Library of Australia offers a "discovery experience" that includes random sampling of its digital collections. Built by Tim Sherratt, the TroveNewsBot program pulls random content from digitized Australian newspapers from I 803 to the mid-I950s, posting headlines to Twitter and illustrations to an associated Tumblr account. Sherratt has also built experimental tools like "Headline Roulette" and "The Future of the Past," each of which randomly harvests from Trove's archive and delivers a visual discovery interface. ${ }^{\text {10 }}$ The paired Twitter and Tumblr accounts featuring "Historical Book Images," built by Mark Sample, take a similar approach to randomly sampling historical book illustrations within the Internet Archive. ${ }^{\text {II }}$ At the British Library, the Digital Scholarship Department created "The Mechanical Curator" to push "randomly selected small illustrations and ornamentations" from seventeenth- to nineteenth-century books 
to its own Tumblr site. ${ }^{\mathrm{I2}}$ As one of its developers suggests, the project offers one way of opening digital collections to the perennial research desk question: "How do you find things that you cannot begin to describe?" ${ }_{3}$ To put this differently, how do you discover things you did not know to look for?

These machines of serendipity sometimes offer simple shifts of perspective. For instance, the "StackView" browsing tool developed at Harvard's Library Lab shows search results by virtual book spines. The project underscores the importance of the "visual layout of [the] interface on browsing outcomes" and tries to find what Gabrielle Dean calls "that sweet spot of 'unexpected but relevant." "'4 An in-development project called STAK (Serendipitous Tool for Augmenting Knowledge), by Kim Martin, aims to create an application for mobile devices that will suggest proximate resources based on users' physical locations within a given library. ${ }^{\mathrm{Is}}$ The Bohemian Bookshelf project offers "five interlinked visualizations" keyed to other aspects of library collections, including the "tangible qualities of books such as cover colour and page count, temporal aspects such as publication year and content era, as well as content data such as keywords and books' author." ${ }^{16}$ These visual discovery interfaces may be especially relevant for nineteenth-century texts and periodicals which, because of their abiding ordinariness, are targets for de-accessioning and are disappearing from library shelves. ${ }^{17}$

Victorianist Dan Cohen, now director of the Digital Public Library of America (DPLA), has also considered how "to create environments in which serendipity is able to flourish." ${ }^{18}$ Cohen points out the governing paradox: How do you actually plot the unexpected or program serendipity without prearranging the results? For its part, the DPLA offers an Application Programming Interface (API) which lets users and their machines grab, play with, and sort the DPLA's data. Seeking just such a way to "query for random items" in the DPLA, Mark Sample built the Twitter "DPLA Bot" to post "random finds" and "add what we all love about librariesserendipity." I9 At the 2013 "One Week I One Tool" project, a number of digital humanists, designers, and programmers convened to develop a "serendipity engine" that harvests results from the APIs of multiple digital libraries. This engine drives "Serendip-o-matic," an experimental research interface which neither offers a field for directed searching (in other words, Googling) nor returns random or unsupervised results. Instead, it processes chunks of text or citation lists and uses that information to query multiple collections according to its own algorithm. ${ }^{20}$ "Let your sources surprise you," reads the tagline. ${ }^{2 \mathrm{I}}$

So let us. What happens when Leary's own essay about electronic serendipity gets fed into the Serendip-o-matic? The results include an edition of Eminent Victorians from HathiTrust; a I930s poster for the Victorian 
railways from Trove; several pictorial examples of architectural restorations of Victorian houses from the US National Archives; an I885 piece of ephemera printed in London advertising a "New Religious Movement Started by Charles Whitmore Stokes"; and a grayscale photograph of a young girl searching the rubble of a home damaged in the Great Timber Yard Fire in Hartlepool, I922. These documents depict a snapshot historiography of the Victorian past; they testify to Victorian afterlives, to the sifting and renovation of historical debris. If fortuitously discovered, what do these results mean? Their stories have yet to be written. But their electronic encounter echoes, in ways that Leary well understood, the unique methodological challenges facing Victorianists and especially researchers of periodicals, who seek coherence from forms necessarily fragmentary and networked, miscellaneous and serialized. ${ }^{22}$

Perhaps the field of periodicals research should especially embrace serendipity in its technologies and scholarly techniques. For Victorian periodicals were already a technology of serendipity in print. They allowed and rewarded a full spectrum of programmatic and random ways of discovering their contents. For scholars or other readers, discovery results less from directed searching than from all the tangents encountered on the way. ${ }^{23}$ Thus, sources which are plural, redundant, and tangent-rich help promote discovery by the proliferating contingencies of their usage. By developing techniques of serendipity in digital scholarship, we remediate perhaps the most unique feature of the Victorians' own machines of discovery.

North Carolina State University

\section{NOTES}

I. Patrick Leary, "Googling the Victorians," Journal of Victorian Culture Iо, no. I (2005): 72.

2. Ibid., 73, 74. I mean "casual" in its historical sense, which the Oxford English Dictionary defines as "subject to, depending on, or produced by chance; accidental, fortuitous" and "occurring or brought about without design or premeditation."

3. Joanne Shattock and Michael Wolff, eds., The Victorian Periodical Press: Samplings and Soundings (Leicester: Leicester University Press, I982), $\mathrm{x}$. For more on the history of chance discovery in Victorian periodicals, see Paul Fyfe, "The Random Selection of Victorian New Media," Victorian Periodicals Review 42, no. I (Spring 2009): I-23.

4. I am grateful to the attendees of the "Periodical Method" panel at the 20I4 RSVP Conference, University of Delaware, who contributed to a rewarding discussion of this paper and helped sharpen many of its guiding insights, including this one from Troy Bassett. 
5. This includes Google Books, which somewhat amazingly came after Leary's piece. Officially launched in December 2003, it was only promoted the following year as "Google Print" and the "Google Library Project" before being renamed by late 2005 as "Google Book Search." See "Google Books History,” Google Books, accessed October 3, 2013, http://www.google. com/googlebooks/about/history.html; “Our History in Depth,” Google, accessed October 3, 20I3, http://www.google.com/about/company/history; and "Google Books," Wikipedia, accessed September 23, 2013, http:// en.wikipedia.org/w/index.php?title=Google_Books\&oldid=5729504I 7 . See also the Wayback Machine's snapshot of the Google Print page on the last day of 2004: http://web.archive.org/web/2004I 23 I08 $5804 /$ http://print. google.com.

6. That lovely phrase "curatorial intelligence" was furnished by a member of our panel's audience in Delaware. I want to express my gratitude to this person and my apologies for, amid the discussion, not getting her name.

7. As Leary also suggested, the ordinary techniques of scholarship, that invisible middle ground between tool and method ungraciously known as "workflow," are the best measures of our digital transformations. Leary, "Googling the Victorians," 73.

8. For example, see Google's own "I'm Feeling Lucky” button. For a snapshot of Google's front page in December 2004, see the Wayback Machine: http:// web.archive.org/web/2004 I 2 I 8 I 2 I 347/http://www.google.com.

9. "Oxford English Dictionary," Oxford English Dictionary, 201 5, http:// www.oed.com; "Oxford Dictionary of National Biography," Oxford Dictionary of National Biography, 2004-201 5, http://www.oxforddnb.com.

ı.. “TroveNewsBot (@TroveNewsBot),” Twitter, 20I3, https://twitter.com/ TroveNewsBot; "TroveNewsBot Selects," Tumblr, 20I3, http://trovenewsbot.tumblr.com; Tim Sherratt, "Headline Roulette," Wragge Labs, 20I4, http://wraggelabs.com/shed/headline-roulette; Tim Sherratt, "The Future of the Past," Wragge Labs, 20I4, http://newspapers.wraggelabs.com/fotp.

I I. Mark Sample, “Old Book Pics (@BookImages),” Twitter, 20 I4, https:// twitter.com/BookImages; Mark Sample, "Historical Book Images,” Tumblr, 20I4, http://historicalbookimages.tumblr.com.

I2. James Baker, “The Mechanical Curator," Digital Scholarship Blog, September 30, 2013, http://britishlibrary.typepad.co.uk/digital-scholarship/2013/og/the-mechanical-curator.html. See the corresponding Tumblr site at http://mechanicalcurator.tumblr.com.

I3. Ben O'Steen, "Peeking behind the Curtain of the Mechanical Curator," Digital Scholarship Blog, October 7, 2013, http://britishlibrary.typepad.co.uk/ digital-scholarship/2013/Io/peeking-behind-the-curtain-of-the-mechanicalcurator.html.

I4. Gabrielle Dean, "Browsing, Serendipity, and Virtual Discovery," The Sheridan Libraries Blog, October I I, 20I3, http://blogs.library.jhu.edu/word- 
press/20I3/Io/browsing-serendipity-and-virtual-discovery; "Stack View," Harvard Library Innovation Lab, 20I2, http://librarylab.law.harvard.edu/ blog/stack-view.

I 5. Kim Martin and John Simpson, "Serendipity Nouveau," colloquium presentation, Digital Humanities Summer Institute, University of Victoria, BC, June 3, 20I4; Kim Martin, Question Answering, Serendipity, and the Research Process of Scholars in the Humanities, Access Conference, YouTube, 20I2, https://www.youtube.com/watch? v=MVPBon 5mwrs\&feature= youtube_gdata_player.

I6. Alice Thudt, Uta Hinrichs, and Sheelagh Carpendale, "The Bohemian Bookshelf: Supporting Serendipitous Book Discoveries through Information Visualization," The Bohemian Bookshelf, accessed January I 5, 20I 5, http:// www.alicethudt.de/BohemianBookshelf.

I7. Andrew Stauffer, "The Troubled Future of the Nineteenth-Century Book," The Hoarding (blog), March I9, 201 2, http://thehoarding.wordpress. $\mathrm{com} / 20 \mathrm{I}_{2} / \mathrm{O}_{3} / \mathrm{I} 9 /$ the-troubled-future-of-the-nineteenth-century-book-essay.

I 8. Dan Cohen, "Planning for Serendipity," Digital Public Library of America, February 7, 20I4, http://dp.la/info/20I4/O2/o7/planning-for-serendipity.

I9. Mark Sample, “The @dpla API (@samplereality),” Twitter, July 4, 20I3. https://twitter.com/samplereality/status/3527786687597 I I 747.

20. "Serendip-O-Matic: Let Your Sources Surprise You," Serendip-O-Matic, 20I3, http://serendipomatic.org.

2I. Ibid.

22. See also Jim Mussell, The Nineteenth-Century Press in the Digital Age (New York: Palgrave Macmillan, 20I2).

23. "How Do Simple Questions Lead To Big Discoveries?" TED Radio Hour, September I 2, 20I4, http://www.npr.org/20I4/o9/I 2/342I 4729I/how-dosimple-questions-lead-to-big-discoveries. 